\title{
Basal Plasma Glucagon Levels of Man*
}

\author{
Joseph E. Sokal $\dagger$ and Ediz Z. Ezdinli with the assistance of \\ Carol Schiller and Ann Dobbins
}

(From the Department of Medicine, Roswell Park Memorial Institute, New York State

Department of Health, Buffalo, N. Y.)

\begin{abstract}
Summary. The isolated perfused rat liver can serve as a bioassay system for glucagon, capable of detecting $10 \mathrm{~m} \mu \mathrm{g}$ of this agent. Seven $15-\mathrm{ml}$ plasma specimens obtained from different healthy volunteers after an overnight fast were assayed in this system; glucagon could not be detected in any of them, indicating concentrations significantly below $0.67 \mathrm{~m} \mu \mathrm{g}$ per $\mathrm{ml}$ in all subjects. The effects of administering small doses of glucagon to patients were consistent with these results; imposition of increments to plasma glucagon concentration below $1 \mathrm{~m} \mu \mathrm{g}$ per $\mathrm{ml}$ induced distinct and sustained increases in blood glucose.

Observations of the biologic effects of glucagon, together with data on the rate of its inactivation by the liver, suggest that the basal concentration of this hormone in peripheral plasma probably does not exceed $0.1 \mathrm{~m} \mu \mathrm{g}$ per $\mathrm{ml}$.
\end{abstract}

\section{Introduction}

Substantial evidence suggests that glucagon is a hormone playing an essential role in blood glucose homeostasis (1). Among the studies supporting a physiologic function for glucagon are those of Unger, Eisentraut, McCall, and Madison (2), showing that glucagon concentrations in the portal system rise in response to hypoglycemia and fall when hypoglycemia is terminated by intravenous glucose injection. These investigators determined plasma glucagon levels by a radioimmunochemical method and reported basal values averaging 0.5 $\mathrm{m} \mu \mathrm{g}$ per $\mathrm{ml}$ in the pancreaticoduodenal veins of dogs after an overnight fast, and a mean value of $2 \mathrm{~m} \mu \mathrm{g}$ per $\mathrm{ml}$ during acute insulin hypoglycemia. Their data are in good agreement with results of studies in our laboratory of the concentrations of glucagon required to induce slight to maximal hepatic glycogenolysis in isolated rat livers (3).

Recently, there has been considerable interest in utilization of radioimmunochemical assay tech-

* Submitted for publication October 13, 1966; accepted January $17,1967$.

Supported in part by grant A-1646 from the National Institute for Arthritis and Metabolic Diseases.

† Address requests for reprints to Dr. Joseph E. Sokal, Roswell Park Memorial Institute, Buffalo, N. Y. 14203. niques to determine plasma glucagon levels of man. Initial publications on this subject reported quite divergent values for glucagon levels in peripheral blood of normal individuals $(4-7)$, as well as contradictory findings regarding the effects of starvation on the plasma glucagon concentration $(4,6,7)$. A recent research symposium on glucagon (8) failed to clarify this situation; some investigators revised their previously published figures, but no consensus was reached. Average normal values reported by different groups ranged from $0.1 \mathrm{~m} \mu \mathrm{g}$ per $\mathrm{ml}$ of plasma to $5 \mathrm{~m} \mu \mathrm{g}$ per $\mathrm{ml}$.

Resolution of this controversy among different investigators using similar assay methods, and a decision regarding the order of magnitude of the basal plasma glucagon concentration, are crucial to a proper interpretation of the physiological role of this agent. Since the present controversy centers on the validity of complex radioimmunologic techniques for measurement of glucagon concentration, it seemed desirable to use completely different methods to obtain data that might resolve it. Accordingly, we undertook two series of experiments that offered hope of identifying the order of magnitude of human plasma glucagon levels by measurements of biological activity. One study utilized the isolated perfused rat liver as a bio- 
assay system for glucagon. In previous work with this system, we had demonstrated that the rat liver is quite sensitive to the action of this agent and that several effects can be detected soon after the addition of small amounts of glucagon to the blood perfusing a glycogen-containing liver. These effects include an increase in hepatic phosphorylase activity (9), an increase in hepatic glucose output $(1,9,10)$, a rise in glucose concentration of the perfusing blood $(3,10)$, and a fall in hepatic glycogen content (3). The second study was performed with the cooperation of hospitalized patients of this Institute and constituted, in essence, a confirmation of the report of Butterfield, Fry, and Whichelow (11) on the sensitivity of man to small doses of glucagon. Such data constitute indirect evidence from which some conclusions may be drawn regarding the order of magnitude of the basal concentration of glucagon.

\section{Methods}

Liver perfusions. The liver perfusion system in use in this laboratory has been described previously (10). Normal male Sprague-Dawley rats were used as liver and blood donors. An equilibration period of $45 \mathrm{~min}-$ utes was allowed after establishment of perfusion to permit the hepatic glucose output to stabilize. Collection of base-line data was then begun. A liver specimen was obtained for determinations of glycogen and phosphorylase activity. Blood specimens were obtained from the hepatic inflow (just proximal to the portal vein cannula) and from the hepatic outflow cannula. Additional specimens of liver and of hepatic inflow and outflow blood were obtained 15 and 30 minutes later (at 60 and 75 minutes of perfusion): Immediately after the third base-line samples were obtained, $15 \mathrm{ml}$ of "artificial plasma" (10) or of normal human plasma, with or without added glucagon, was added to the blood reservoir, bringing the total blood volume in the system to $120 \mathrm{ml}$. Additional liver and blood specimens were obtained at 81 minutes of perfusion ( 5 to 6 minutes after additions to the blood reservoir), by which time a little over half the total blood volume would have passed through the liver; at $85 \mathrm{~min}$ utes, by which time the entire blood volume would ordinarily have circulated through the liver and mixing would be complete; and at 95 minutes, by which time glucagon concentrations would have declined from peak values as a result of hepatic inactivation of the agent (3).

Hepatic inflow and outflow blood glucose concentrations were determined on triplicate blood samples by a Technicon Autoanalyzer with a ferricyanide reduction method. The micromethod, with two stage dialysis and a slow cycling time, was applied to supernatants obtained by laking the blood and precipitating the proteins. In our hands, this technique gives values reproducible within $3 \%$. The mean outflow-inflow difference was multiplied by the blood flow rate through the liver, measured at the sampling time, to give the net hepatic glucose output. Liver glycogen was determined by the method of Good, Kramer, and Somogyi (12) using the Autoanalyzer for the determinations of glucose after hydrolysis. Phosphorylase activity was determined in duplicate by a modification of the method of Cahill, Zottu, and Earle (13). Liver specimens for phosphorylase determination were obtained from sites previously shown to give reproducible values (9).

Venous blood was obtained with heparinized syringes between $8: 30$ and 9:30 a.m. from seven healthy adult volunteers who had not eaten since the previous evening. Plasma was separated in a refrigerated centrifuge and stored at $4^{\circ} \mathrm{C}$ until use (about 2 hours after blood was drawn). Glucagon, ${ }^{1}$ or an equal volume of Ringer's solution, was added to $15 \mathrm{ml}$ of plasma shortly before use. In two experiments, glucagon was added to plasma specimens immediately after centrifugation of the blood, and plasma containing glucagon was allowed to stand at room temperature for 2 hours before use.

Two liver perfusions were performed simultaneously in most experiments. They were started with aliquots from a single pool of normal rat blood. At the end of the base-line periods, human or artificial plasma containing glucagon was added to one system; an equal volume without glucagon was added to the other.

Clinical studies. Glucagon infusions were administered to adult volunteers hospitalized at this Institute. Their diagnoses varied, but none had known diseases of carbohydrate metabolism and all were in good nutritional status. Studies were performed in the morning, after an overnight fast, and breakfast was deferred until completion of glucagon infusion. Physiological saline was infused intravenously at a rate of about $2 \mathrm{ml}$ per minute for 1 hour. Arterialized capillary blood specimens were obtained from warmed fingertips 30,45 , and 60 minutes after starting the infusion. A loading dose of $2.8 \mu \mathrm{g}$ of glucagon (approximately $1 \mu \mathrm{g}$ per L of plasma volume) was then injected through the infusion tubing. After this, the infusion was changed to physiological saline containing glucagon $(0.25 \mu \mathrm{g}$ per $\mathrm{ml})$, which was delivered at a rate of $2 \mathrm{ml}$ per minute. This rate of glucagon infusion was designed to compensate for estimated hepatic inactivation of the agent and was selected on the basis of the following assumptions: that cardiac output was approximately $4 \mathrm{~L}$ per minute, that hepatic blood flow was approximately $25 \%$ of cardiac output, and that $75 \%$ of the glucagon in blood entering the liver is inactivated during a single passage through this organ (3, 14). Capillary blood specimens were obtained 5,15 , and 30 minutes after injection of the loading doses.

\section{Results}

Liver perfusions. Of a total of 30 liver perfusions, one pair (a control and a glucagon standard) was discarded because the preparations failed

\footnotetext{
1 Eli Lilly, Indianapolis, Ind.
} 
to stabilize, and glycogenolysis occurred during the base-line periods. The following analysis is based on data from the remaining experiments, which consisted of the following groups of seven perfusions each:

Control. After the final base-line specimens had been obtained ( 75 minutes of perfusion), $15 \mathrm{ml}$ of artificial plasma was added to the blood reservoir.

Glucagon standard. Artificial plasma containing $10 \mathrm{~m} \mu \mathrm{g}$ of glucagon was added to the blood reservoir at 75 minutes. These additions resulted in peak plasma concentrations of about $0.13 \mathrm{~m} \mu \mathrm{g}$ per $\mathrm{ml}$.

Human plasma. Aliquots of plasma $(15 \mathrm{ml})$ obtained from different healthy adults were added at 75 minutes. The effects of these additions were compared to those in the control and glucagon standard groups.
Human plasma plus glucagon. Additions consisted of $15-\mathrm{ml}$ aliquots of human plasma (from the same specimens used for the previous group) containing $20 \mathrm{~m} \mu \mathrm{g}$ of added glucagon. These experiments constituted "positive controls" and served to rule out the possibility that human plasma might contain glucagon antagonists or other factors inhibiting the effect of this agent on the isolated rat liver. In two of these experiments, plasma specimens containing glucagon were allowed to stand at room temperature for 2 hours before use to determine whether the added glucagon would be inactivated under these conditions. The effects were only moderately less intense than those in the other five experiments, and all data were pooled.

The values for phosphorylase activity obtained in these experiments are listed in Table I. Indi-

TABLE I

Hepatic phosphorylase activity during base-line and experimental periods in 28 liver perfusions

\begin{tabular}{|c|c|c|c|c|c|c|c|c|}
\hline \multirow{2}{*}{$\begin{array}{l}\text { Perfusion } \\
\text { no. }\end{array}$} & \multicolumn{4}{|c|}{ Base-line period } & \multicolumn{4}{|c|}{ Experimental period } \\
\hline & $45 \mathrm{~min}$ & $60 \mathrm{~min}$ & $75 \mathrm{~min}$ & Mean & $81 \mathrm{~min}$ & $85 \mathrm{~min}$ & $95 \mathrm{~min}$ & Mean \\
\hline \multicolumn{9}{|c|}{ Amoles $\mathrm{PO}_{4} /$ minute $/ \mathrm{g}$ liver } \\
\hline \multicolumn{9}{|c|}{ Control: $15 \mathrm{ml}$ of "artificial plasma" added } \\
\hline $\begin{array}{l}822 A \\
824 A \\
828 B \\
830 A \\
836 A \\
839 B \\
839 C\end{array}$ & $\begin{array}{l}14.1 \\
11.6 \\
13.8 \\
12.9 \\
11.7 \\
12.9 \\
14.4\end{array}$ & $\begin{array}{l}12.4 \\
11.5 \\
13.9 \\
17.0 \\
13.3 \\
16.0 \\
12.8\end{array}$ & $\begin{array}{r}13.6 \\
11.8 \\
9.9 \\
15.1 \\
12.2 \\
13.9 \\
18.1\end{array}$ & $\begin{array}{l}13.4 \\
11.6 \\
12.5 \\
15.0 \\
12.4 \\
14.3 \\
15.1\end{array}$ & $\begin{array}{r}14.4 \\
9.8 \\
14.3 \\
14.3 \\
9.8 \\
14.1 \\
17.6\end{array}$ & $\begin{array}{l}18.4 \\
11.8 \\
13.9 \\
17.0 \\
13.3 \\
16.7 \\
16.8\end{array}$ & $\begin{array}{r}15.1 \\
9.8 \\
17.0 \\
14.3 \\
11.7 \\
8.7 \\
16.5\end{array}$ & $\begin{array}{l}16.0 \\
10.5 \\
15.1 \\
15.2 \\
11.6 \\
13.2 \\
17.0\end{array}$ \\
\hline \multicolumn{9}{|c|}{ Glucagon standard: $10 \mathrm{~m} \mu \mathrm{g}$ of glucagon $+15 \mathrm{ml}$ of "artificial plasma" added } \\
\hline $\begin{array}{l}818 \mathrm{~A} \\
822 \mathrm{~B} \\
824 \mathrm{~B} \\
828 \mathrm{~A} \\
830 \mathrm{~B} \\
836 \mathrm{~B} \\
839 \mathrm{~A}\end{array}$ & $\begin{array}{r}13.8 \\
11.5 \\
15.1 \\
13.3 \\
8.7 \\
15.7 \\
13.0\end{array}$ & $\begin{array}{r}11.6 \\
8.4 \\
13.3 \\
13.1 \\
7.5 \\
14.3 \\
11.4\end{array}$ & $\begin{array}{r}12.3 \\
8.2 \\
12.8 \\
11.8 \\
6.8 \\
17.0 \\
11.5\end{array}$ & $\begin{array}{r}12.6 \\
9.4 \\
13.7 \\
12.7 \\
7.7 \\
15.7 \\
14.3\end{array}$ & $\begin{array}{r}16.5 \\
13.7 \\
16.1 \\
13.6 \\
8.7 \\
18.9 \\
18.1\end{array}$ & $\begin{array}{r}18.5 \\
18.2 \\
20.1 \\
14.9 \\
6.0 \\
18.8 \\
17.3\end{array}$ & $\begin{array}{r}16.5 \\
15.4 \\
16.9 \\
13.0 \\
9.8 \\
15.0 \\
16.8\end{array}$ & $\begin{array}{r}17.2 \\
15.8 \\
17.7 \\
13.8 \\
8.2 \\
17.6 \\
17.4\end{array}$ \\
\hline \multicolumn{9}{|c|}{ Human plasma: $15 \mathrm{ml}$ of human plasma added } \\
\hline $\begin{array}{l}803 \mathrm{~A} \\
807 \mathrm{~B} \\
810 \mathrm{~A} \\
814 \mathrm{~B} \\
815 \mathrm{~A} \\
816 \mathrm{~A} \\
818 \mathrm{~B}\end{array}$ & $\begin{array}{r}12.9 \\
8.2 \\
12.5 \\
16.2 \\
16.0 \\
13.5 \\
11.9\end{array}$ & $\begin{array}{r}12.2 \\
9.0 \\
12.4 \\
6.8 \\
16.9 \\
13.5 \\
13.2\end{array}$ & $\begin{array}{r}12.1 \\
7.1 \\
11.5 \\
11.2 \\
15.6 \\
10.9 \\
12.2\end{array}$ & $\begin{array}{r}12.4 \\
8.1 \\
12.1 \\
11.4 \\
16.2 \\
12.6 \\
12.4\end{array}$ & $\begin{array}{r}12.4 \\
7.1 \\
10.1 \\
10.2 \\
15.2 \\
13.8 \\
14.2\end{array}$ & $\begin{array}{r}13.2 \\
9.2 \\
12.5 \\
11.0 \\
17.1 \\
13.5 \\
14.2\end{array}$ & $\begin{array}{r}12.4 \\
9.5 \\
15.1 \\
11.7 \\
12.5 \\
15.2 \\
16.5\end{array}$ & $\begin{array}{r}12.7 \\
8.6 \\
12.6 \\
11.0 \\
14.9 \\
14.2 \\
15.0\end{array}$ \\
\hline \multicolumn{9}{|c|}{ Human plasma + glucagon : $20 \mathrm{~m} \mu \mathrm{g}$ of glucagon $+15 \mathrm{ml}$ of plasma added } \\
\hline $\begin{array}{l}807 \mathrm{~A} \\
810 \mathrm{~B} \\
814 \mathrm{~A} \\
815 \mathrm{~B} \\
816 \mathrm{~B} \\
835 \mathrm{~A} \\
835 \mathrm{~B}\end{array}$ & $\begin{array}{r}8.5 \\
8.9 \\
12.9 \\
9.6 \\
4.4 \\
5.5\end{array}$ & $\begin{array}{r}6.7 \\
12.7 \\
13.7 \\
9.6 \\
4.8 \\
10.1\end{array}$ & $\begin{array}{r}8.1 \\
16.7 \\
12.6 \\
15.0 \\
10.2 \\
8.9 \\
8.2\end{array}$ & $\begin{array}{r}7.8 \\
12.8 \\
12.6 \\
13.9 \\
9.8 \\
6.0 \\
7.9\end{array}$ & $\begin{array}{l}15.7 \\
14.5 \\
15.5 \\
14.2 \\
14.5 \\
10.1 \\
10.9\end{array}$ & $\begin{array}{r}14.3 \\
14.8 \\
17.1 \\
17.1 \\
15.8 \\
9.8 \\
11.9\end{array}$ & $\begin{array}{r}14.9 \\
16.4 \\
15.4 \\
17.1 \\
13.5 \\
9.2 \\
11.5\end{array}$ & $\begin{array}{r}15.0 \\
15.2 \\
16.0 \\
16.1 \\
14.6 \\
9.7 \\
11.4\end{array}$ \\
\hline
\end{tabular}




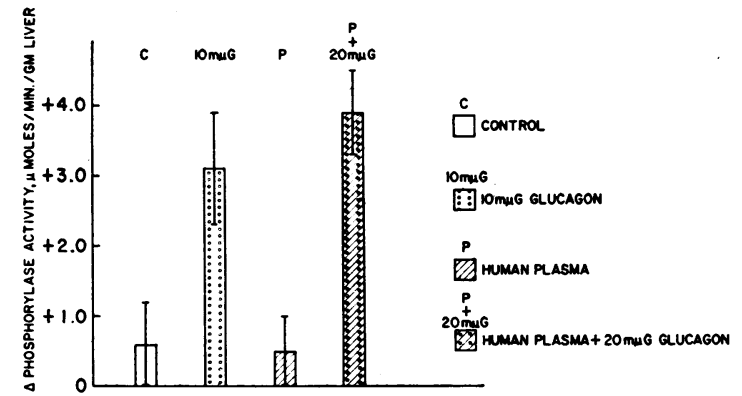

Fig. 1. Mean increases in Phosphorylase activity DURING THE EXPERIMENTAL PERIODS. Each group consisted of seven perfusions. Vertical bars represent standard errors.

vidual values varied over a relatively large range, and there were a number of unexplained fluctuations among successive specimens from the same liver. In about half of the base-line and experimental periods, however, very good agreement was obtained, with all three values falling within $2 \mathrm{U}$ of each other. There were no significant changes in phosphorylase activity during the baseline periods or during the experimental periods in any group of perfusions. Accordingly, the baseline and experimental values in each experiment were averaged, and the differences among the means were compared. The results are shown in Figure 1. It is evident that addition of $15 \mathrm{ml}$ of human plasma to the perfusing blood did not have a significant effect on hepatic phosphorylase activity. In contrast, the presence of $10 \mathrm{~m} \mu \mathrm{g}$ of glucagon in artificial plasma, and of $20 \mathrm{~m} \mu \mathrm{g}$ in human plasma, was readily detected by phosphorylase assay $(\mathrm{p}<0.05, \mathrm{p}<0.01$, respectively). This assay could not discriminate between the two different dose levels of glucagon, however.

The mean base-line glucose output rates for individual livers varied from small negative values to $0.3 \mathrm{mg}$ per minute per $\mathrm{g}$ (Table II). Despite the unavoidable inaccuracies in calculations based on small differences in glucose concentration, agreement among successive values for individual livers was quite satisfactory; in the majority of perfusions, the maximal variation among the three base-line values did not exceed $0.15 \mathrm{mg}$ per minute per g. Table II also presents the individual values for hepatic glucose output during the experimental periods, as well as the data used to calculate them. For each perfusion, the mean base-line value was subtracted from each experimental value to give the increment in glucose output at each sampling time during the experimental period. Figure 2 presents the means of these increments for the four groups of perfusions. Of interest is the fact that in none of the $10-\mathrm{m} \mu \mathrm{g}$ glucagon standard perfusions could a rise in hepatic glucose output be detected at the 81-minute point. In contrast, 4 minutes later, a clear-cut increase ( $p<0.01$ ) was seen. By 95 minutes, glucose production was clearly below peak levels. Additions of $15 \mathrm{ml}$ of human plasma did not induce a significant rise in glucose output at any time. When human plasma containing $20 \mathrm{~m} \mu \mathrm{g}$ of glucagon was added, an increase in hepatic glucose output was demonstrable at 81 minutes $(\mathrm{p}<0.01)$ as well as at 85 minutes $(p<0.01)$, and the mean rise over the experimental period was significantly greater than that in the $10-\mathrm{m} \mu \mathrm{g}$ glucagon standard perfusions $(p<0.05)$. Thus, in contrast to phosphorylase assay, measurement of the hepatic glucose output proved capable of discriminating between these two groups.

Analysis of the changes in circulating blood glucose concentration confirmed the results of measurement of hepatic glucose output. In each perfusion, the rate of increase in perfusing blood glucose during the experimental period was compared to that during the base-line period. The mean changes during the two time intervals of the experimental period, 81 to 85 minutes and 85 to 95 minutes, are shown in Figure 3. As with the data for hepatic glucose output, these figures permit

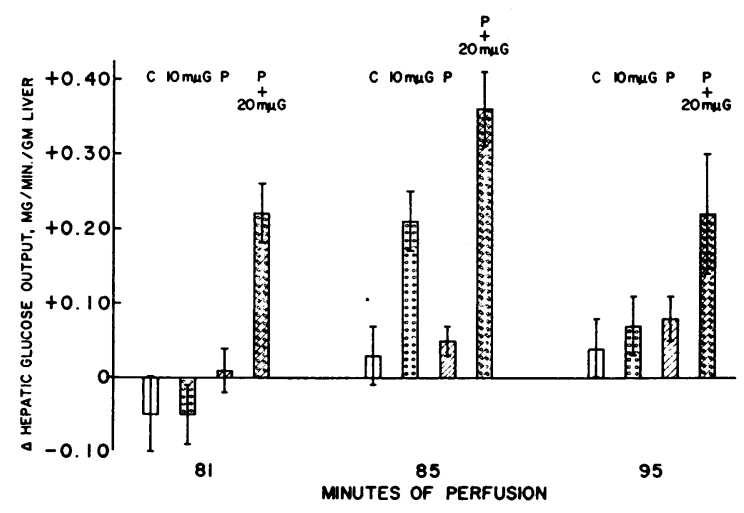

Fig. 2. Changes in hepatic glucose output from MEAN BASE-LINE VALUES AT INDICATED TIMES DURING THE EXPERIMENTAL PERIODS. Symbols as in Figure 1. 


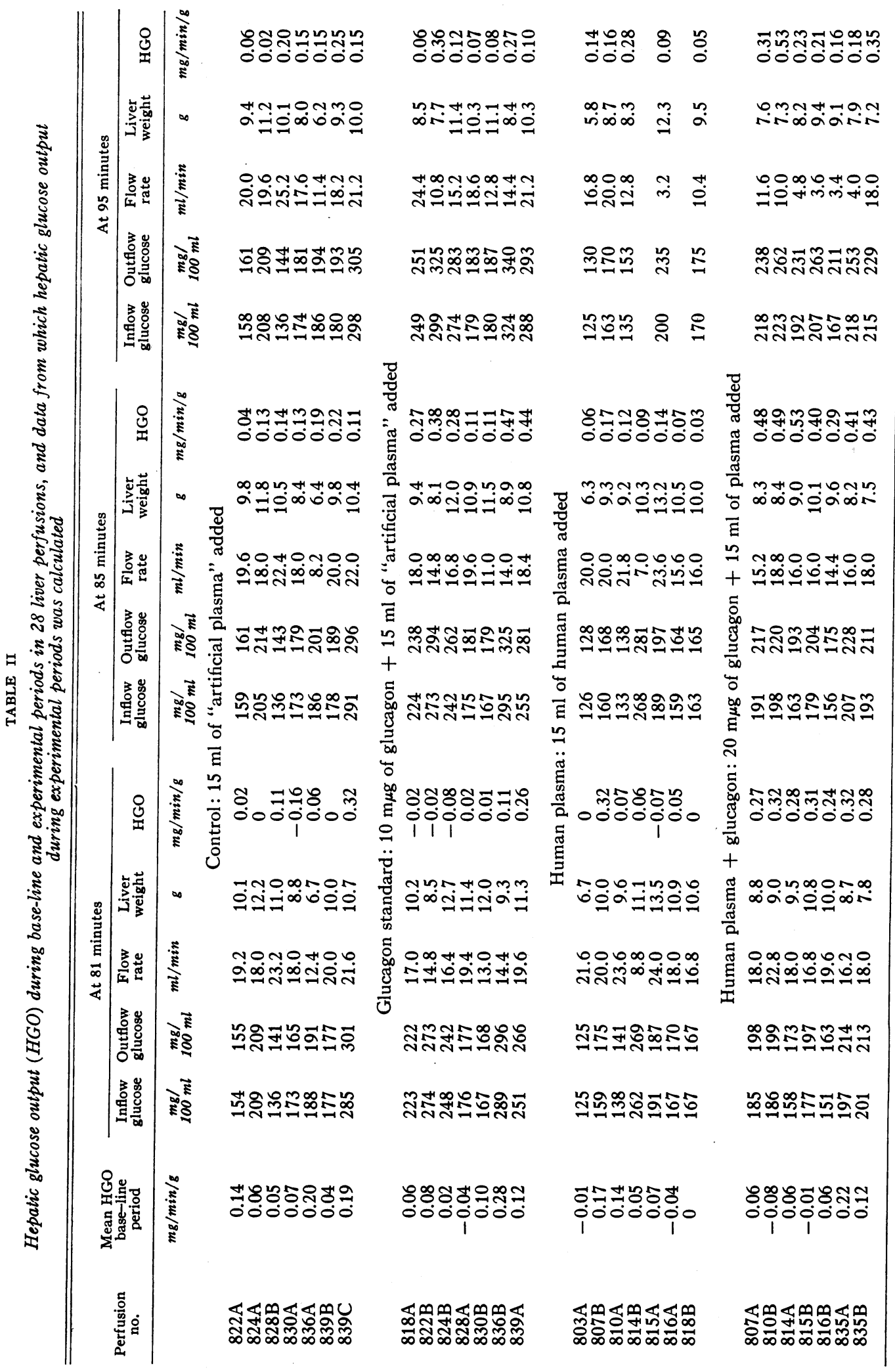




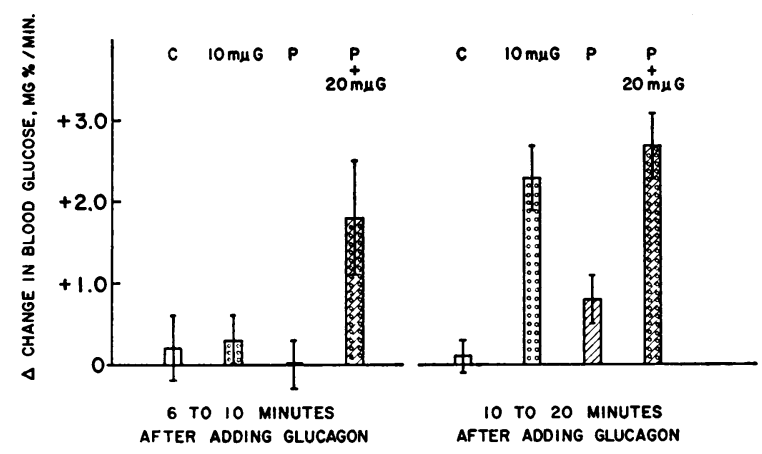

Fig. 3. Changes in rate of InCRease of the PERFUSING BLOOD GLUCOSE CONCENTRATION FROM MEAN BASELINE VALUES DURING TWO INTERVALS OF THE EXPERIMENTAL PERIODS. Symbols as in Figure 1.

differentiation between the two dose levels of glucagon. The larger amount given with human plasma induced earlier and faster increases in circulating blood glucose than the $10-\mathrm{m} \mu \mathrm{g}$ standard addition. The effect of $15 \mathrm{ml}$ of human plasma was clearly less than that of $10 \mathrm{~m} \mu \mathrm{g}$ of glucagon $(\mathrm{p}<0.01)$ and was not significantly different from that of artificial plasma ( $p>0.05)$.

No significant changes in liver glycogen concentration were observed in any of the experimental groups. There were slight decreases in average glycogen values in the two groups of perfusions to which glucagon had been added, as compared to those in which additions consisted of artificial or human plasma alone. Even when these data were pooled, however, the changes were not statistically significant $(p>0.10)$.

It was clear from the data presented above that there was less evidence of glucagon action in the group of perfusions with additions of normal human plasma than in the standard group receiving $10 \mathrm{~m} \mu \mathrm{g}$ glucagon. To determine whether this was due to a consistently lower concentration of glucagon or to the averaging of figures for a few specimens containing more glucagon with several containing none at all, we reviewed the data from individual perfusions. The results are summarized in Table III. Although some increases in phosphorylase activity, hepatic glucose output, and the rate of rise of blood glucose concentration were seen in the seven experiments with human plasma, there was only one perfusion in which a single change (in phosphorylase activity) exceeded twothirds of the average for the glucagon standard group. This probably reflected experimental variation rather than glucagon effect, since it was also seen twice among the control perfusions. We conclude, therefore, that none of the seven plasma specimens had biologic activity in this system comparable to that of $10 \mathrm{~m} \mu \mathrm{g}$ of glucagon.

Clinical studies. A loading dose of $1 \mu \mathrm{g}$ of glucagon per $\mathrm{L}$ of estimated plasma volume, followed by glucagon infusion at a rate of $0.5 \mu \mathrm{g}$ per minute, was administered to seven hospitalized adults without overt disease of carbohydrate metabolism. Their mean base-line blood glucose concentration was $86 \pm 4$ (SE) $\mathrm{mg}$ per $100 \mathrm{ml}$. There was a slight decrease during 30 minutes of saline infusion. In every case, an increase in capillary blood glucose concentration was observed 5 minutes after injection of the loading dose of glucagon. In

TABLE III

Criteria of glucagon action in individual perfusions

\begin{tabular}{|c|c|c|c|c|}
\hline \multirow[b]{2}{*}{ Change from mean for base-line period } & \multicolumn{4}{|c|}{ No. of perfusions (of 7 in each group) } \\
\hline & Controls & $\begin{array}{c}\text { Glucagon } \\
10 \mathrm{~m} \mu \mathrm{g}\end{array}$ & $\underset{\text { plasma }}{\text { Human }}$ & $\begin{array}{l}\text { Plasma } \\
+\underset{20 \mathrm{~m} \mu \mathrm{g}}{\text { glucagon }} \\
\end{array}$ \\
\hline $\begin{array}{l}\text { Increase in mean phosphorylase activity during experimental period, } \\
>2 \mathrm{U} / \mathrm{g} \text { liver* }\end{array}$ & 2 & 4 & 1 & 7 \\
\hline $\begin{array}{l}\text { Increase in hepatic glucose output at } 85 \text { minutes, } \\
>0.14 \mathrm{mg} / \mathrm{min} / \mathrm{g} \text { liver* }\end{array}$ & 1 & 6 & 0 & 7 \\
\hline $\begin{array}{l}\text { Increase in slope of blood glucose curve between } 85 \text { and } 95 \text { minutes, } \\
>1.5 \mathrm{mg} / 100 \mathrm{ml} / \mathrm{min}^{*}\end{array}$ & 0 & 5 & 0 & 6 \\
\hline Two or more of above & 0 & 5 & 0 & 7 \\
\hline
\end{tabular}

* These limiting values represent two-thirds of the respective mean changes in the $10 \mathrm{~m} \mu \mathrm{g}$ glucagon standard group. 


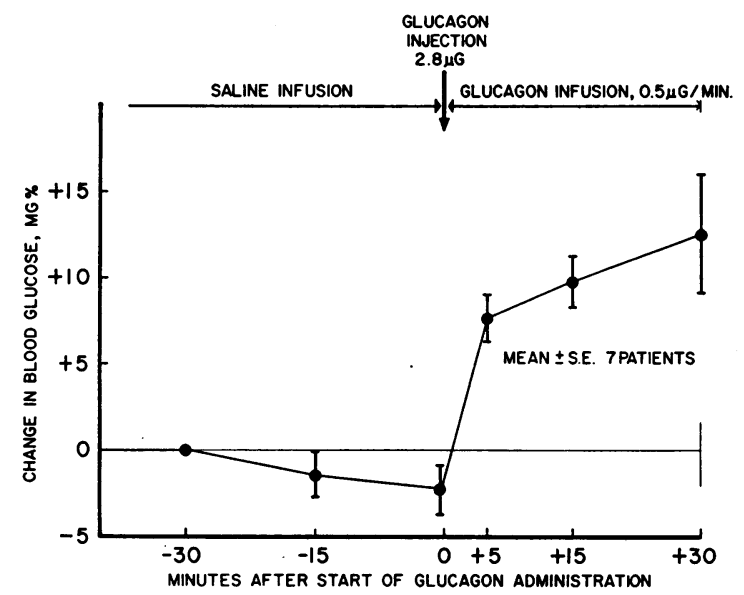

Fig. 4. EFFECT OF A LOADING DOSE OF $2.8 \mu \mathrm{G}$ OF GLUCAGON, FOLLOWED BY INFUSION OF $0.5 \mu$ G PER MINUTE, ON BLOOD GLUCOSE CONCENTRATION OF MAN.

one patient, this was followed by a slight decline during the next 25 minutes, but the final value was still above the base-line level. Two patients manifested a progressive increase in blood glucose concentration during the glucagon infusion. The remaining four showed an identical pattern; the blood glucose concentration rose further between 5 and 15 minutes, but at a slower rate, and remained stable during the final 15 minutes. The mean changes in blood glucose concentration from the initial values ( 30 minutes before glucagon administration) are shown in Figure 4 . The increases over base-line values were highly significant $(p<0.01)$ at all sampling times after the start of glucagon administration.

\section{Discussion}

It is clear that the isolated perfused rat liver can serve as a bioassay system for glucagon, and that it is capable of detecting amounts as small as $10 \mathrm{~m} \mu \mathrm{g}$. Measurement of changes in hepatic glucose output (and in the perfusing blood glucose concentration) proved capable of discriminating between different small amounts of the hormone, whereas determination of increases in phosphorylase activity did not. This is not surprising, since the range of variation in phosphorylase activity is much smaller than that in hepatic glucose output. Phosphorylase activity in perfused rat livers rises by about $75 \%$ during maximal glucagon action (9), whereas hepatic glucose output can increase more than fivefold (10). The failure of liver glycogen assays to detect the effects of 10 to $20 \mathrm{~m} \mu \mathrm{g}$ of glucagon is consistent with our previous experience in this regard (3).

These bioassay data indicate that $15 \mathrm{ml}$ of peripheral plasma obtained from healthy adults after an overnight fast contains significantly less than $10 \mathrm{~m} \mu \mathrm{g}$ of glucagon (i.e., less than $0.67 \mathrm{~m} \mu \mathrm{g}$ per $\mathrm{ml}$ ). Our failure to observe greater effects in this bioassay system cannot be attributed to glucagon antagonists in human plasma or to inactivation of glucagon, since assay after addition of $20 \mathrm{~m} \mu \mathrm{g}$ of glucagon to equal aliquots of the same plasma specimens uniformly gave the expected results. Review of individual experiments confirmed the results reached from analysis of mean values for the group. None of the seven volunteers studied had plasma glucagon levels detectable by this technique (Table III).

The results of glucagon administration to patients confirm the report of Butterfield and his colleagues (11) regarding the sensitivity of man to small doses of this agent. They did not use loading doses, but found that an infusion rate of $2 \mu \mathrm{g}$ per minute produced a progressive increase in blood glucose concentration, with an almost constant slope (about $2 \mathrm{mg}$ per $100 \mathrm{ml}$ per minute) during 20 -minute infusions. We observed a similar slope during the first 5 minutes of glucagon administration (Figure 4). The slower rise during the final 25 minutes of our experiments (Figure 4) is presumably due to the fact that we were using one-fourth of their infusion rate. Of interest is the fact that Butterfield and associates also observed a small increase in blood glucose in a few experiments with a still lower infusion rate, $0.2 \mu \mathrm{g}$ per minute.

It is impossible to make an accurate estimate of the plasma glucagon level maintained in our experiments or in those of Butterfield and associates. Our technique of administration was designed to produce an initial increment approaching $1 \mathrm{~m} \mu \mathrm{g}$ per $\mathrm{ml}$ and to ensure that this was not exceeded at any time thereafter. However, it is very unlikely that such an increment was maintained for more than a minute or two, if it was reached at all. Glucagon has a space of distribution much larger than the blood volume and disappears from the plasma very rapidly (14). Thus, even if our 
infusion rate were somewhat greater than the rate of hepatic inactivation, the plasma concentration would have fallen after injection of the loading dose. Since the blood glucose concentration continued to rise after the first 5 minutes in all but one of our subjects, it would appear that hepatic glycogenolysis can be stimulated by increments significantly less than $1 \mathrm{~m} \mu \mathrm{g}$ per $\mathrm{ml}$. This conclusion is supported by the observation of Butterfield and colleagues that infusion at a rate of 0.2 $\mu \mathrm{g}$ per $\mathrm{ml}$ could induce an increase in blood glucose. Thus, the sensitivity of human liver to glucagon action is probably not greatly different from that of rat liver (3), cat liver (15), and dog liver (16).

If, as seems to be the case, man responds to glucagon in a manner similar to that of other mammalian species so far studied, a portal vein concentration of $1 \mathrm{~m} \mu \mathrm{g}$ per $\mathrm{ml}$ would induce a rate of glycogenolysis much more rapid than that associated with the basal state. The present studies, plus previous experience with rat liver in this laboratory $(3,9)$, indicate that a portal vein concentration of 0.13 to $0.4 \mathrm{~m} \mu \mathrm{g}$ per $\mathrm{ml}$ would be more compatible with the slow rate of glycogenolysis characteristic of the undisturbed fasting state. This would suggest a posthepatic glucagon concentration of 0.03 to $0.1 \mathrm{~m} \mu \mathrm{g}$ per $\mathrm{ml}$.

We conclude that glucagon assay methods in use in several laboratories give erroneously high values. The reasons for this have not yet been satisfactorily clarified (8). However, one group working with radioimmunoassays has recently reported concentrations in peripheral plasma of ten fasting normal subjects ranging from undetectable levels to a maximum of $0.3 \mathrm{~m} \mu \mathrm{g}$ per $\mathrm{ml} \mathrm{(17).}$ These values are in or near the range suggested above. Thus, it appears that bioassay and immunoassay results are not necessarily irreconcilable.

\section{References}

1. Sokal, J. E. Glucagon-an essential hormone. Amer. J. Med. 1966, 41, 331.

2. Unger, R. H., A. M. Eisentraut, M. S. McCall, and L. L. Madison. Measurements of endogenous glucagon in plasma and the influence of blood glu- cose concentration upon its secretion. J. clin. Invest. 1962, 41, 682.

3. Sokal, J. E., E. J. Sarcione, and A. M. Henderson. Relative potency of glucagon and epinephrine as hepatic glycogenolytic agents: studies with the isolated perfused rat liver. Endocrinology 1964, 74, 930.

4. Unger, R. H., A. M. Eisentraut, and L. L. Madison. The effects of total starvation upon the levels of circulating glucagon and insulin in man. J. clin. Invest. 1963, 42, 1031.

5. Samols, E., J. Tyler, G. Marri, and V. Marks. Stimulation of glucagon secretion by oral glucose. Lancet 1965, 2, 1257.

6. Lawrence, A. M. Radioimmunoassayable glucagon levels in man: effects of starvation, hypoglycemia, and glucose administration. Proc. nat. Acad. Sci. (Wash.) 1966, 55, 316.

7. Schalch, D. S. Glucagon regulation in normal and obese diabetic subjects. J. clin. Invest. 1966, 45, 1068.

8. American Diabetes Association, Inc. Research Symposium on Glucagon. San Francisco, October 7-8, 1966.

9. Weintraub, B. D., E. J. Sarcione, and J. E. Sokal. Effect of glucagon on phosphorylase activity in the isolated perfused liver. In preparation.

10. Sokal, J. E., and B. Weintraub. Failure of the isolated liver to react to hypoglycemia. Amer. J. Physiol. 1966, 210, 63.

11. Butterfield, W. J. H., I. K. Fry, and M. J. Whichelow. Some observations on the effect of small doses of glucagon in normal and diabetic subjects. Guy's Hosp. Rep. 1960, 109, 95.

12. Good, C. A., H. Kramer, and M. Somogyi. The determination of glycogen. J. biol. Chem. 1933, 100, 485.

13. Cahill, G. F., Jr., S. Zottu, and A. S. Earle. In vivo effects of glucagon on hepatic glycogen, phosphorylase and glucose-6-phosphatase. Endocrinology 1957, 60, 265.

14. Berson, S. A., R. S. Yalow, and B. W. Volk. In vivo and in vitro metabolism of insulin- $\mathrm{I}^{132}$ and glucagon- ${ }^{181}$ in normal and cortisone-treated rabbits. J. Lab. clin. Med. 1957, 49, 331.

15. Staub, A., L. Sinn, and O. K. Behrens. Purification and crystallization of glucagon. J. biol. Chem. 1955, 214, 619.

16. Ezdinli, E. Z., and J. E. Sokal. A comparison of glucagon and epinephrine effects in the dog. Endocrinology 1966, 78, 47.

17. Crockford, P. M., W. R. Hazzard, and R. H. Williams. Studies in man with a double antibody immunoassay for glucagon. Submitted for publication. 